\title{
ENTRE A SOCIOLOGIA DA SOCIALIZAÇÃO E A SOCIOLOGIA PRAGMÁTICA: DESAFIOS PARA PENSAR AS PRÁTICAS DOCENTES
}

\begin{abstract}
RESUMO: O objetivo deste artigo é tecer uma reflexão teórica a partir do questionamento de como a sociologia da socialização e a sociologia pragmática contribuem para os estudos em sociologia da educação, sendo raras as pesquisas que buscam associar estas duas correntes teóricas. Parte-se do pressuposto que, por mais que haja diferenças e similitudes, as duas teorias são complementares e ajudam a compreender sociologicamente a prática humana e, especificamente, a prática docente. Para averiguar esta hipótese, utiliza-se a literatura franco-luso-brasileira. Conclui-se que as duas correntes sociológicas juntas oferecem instrumentos teóricos e metodológicos para a realização de estudos em sociologia da educação que se preocupam com a complexidade do agir, constitutiva da docência.
\end{abstract}

Gabriela Valente

Palavras-chave: Sociologia da socialização. Sociologia pragmática. Prática docente. Sociologia da educação.

\section{BETWEEN SOCIALIZATION SOCIOLOGY AND PRAGMATIC SOCIOLOGY: CHALLENGES TO THINK TEACHING PRACTICES}

\begin{abstract}
The aim of this article is to provide a theoretical reflection based on the questioning of how the sociology of socialization and pragmatic sociology contribute to studies in the sociology of education, since researches which seek to associate these two theoretical currents are rare. Therefore, we assume that, although there are differences and similarities, the two theories are complementary and help to sociologically understand the human practice, and specifically in this text the teaching practice. To verify this hypothesis, the Franco-PortugueseBrazilian literature that discusses these theories is used. The conclusion reached is that the two sociological currents together offer theoretical and methodological tools to carry out studies in sociology of education that are concerned with the complexity of acting, constitutive of the teaching profession.
\end{abstract}

Keywords: Sociology of socialization. Pragmatic sociology. Teaching practice. Sociology of education.

1.Université Lumière Lyon - Laboratoire Education, Cultures, Politiques - Lyon, França. E-mail: gabriela.abuhab.valente@gmail.com Este texto é fruto de uma pesquisa de doutorado, intitulada "As práticas docentes e a questão religiosa Elementos de comparação entre o Brasil e a França”, orientada por Profa. Maria da Graça J. Setton e com financiamento da FAPESP, Número do processo 2015/22243-8 


\title{
ENTRE LA SOCIOLOGÍA DE LA SOCIALIZACIÓN Y LA SOCIOLOGÍA PRAGMÁTICA: DESAFÍOS PARA PENSAR LAS PRÁCTICAS DE ENSEÑANZA
}

\begin{abstract}
RESUMEN: El objetivo de este artículo es proporcionar una reflexión teórica basada en el cuestionamiento de cómo la sociología de la socialización y la sociología pragmática contribuyen a los estudios en la sociología de la educación. Son raros los estudios que buscan asociar estas dos corrientes teóricas, por lo tanto, suponemos que, aunque existen diferencias y similitudes, las dos teorías son complementarias y ayudan a comprender sociológicamente la práctica humana, y específicamente en este texto la práctica docente. Para verificar esta hipótesis, se utiliza la literatura francoportuguesa-brasileña que discute estas teorías. La conclusión alcanzada es que las dos corrientes sociológicas juntas ofrecen herramientas teóricas y metodológicas para llevar a cabo estudios en sociología de la educación que se ocupan de la complejidad de la actuación, constitutiva de la profesión docente.
\end{abstract}

Palabras-clave: Sociología de la socialización. Sociología pragmática. Práctica docente. Sociologia de la educación.

\section{Introdução}

$\mathrm{O}$ indivíduo, a sociedade e suas relações são os principais objetos de estudo da sociologia. O desenvolvimento desta área do conhecimento permitiu a elaboração de diferentes correntes sociológicas que, por vezes, se contradizem, se ultrapassam ou se complementam. Neste artigo, trabalharemos com duas correntes sociológicas originárias da sociologia francófona que se aproximam pela questão da autonomia das ações: a sociologia pragmática, também conhecida como sociologia da reflexividade individual, das provas ou das justificações, que surgiu na década de 1980 como uma dissonância da sociologia da socialização, também chamada de sociologia das disposições.

Assim, este texto é o resultado de uma reflexão teórica a partir do questionamento de como a sociologia da socialização e a sociologia pragmática podem contribuir para estudos em sociologia da educação e, mais especificamente, para estudos que se debruçam sobre as práticas docentes. Parte-se do pressuposto que, por mais que haja diferenças e similitudes, as duas teorias são complementares e nos ajudam a compreender sociologicamente a prática humana e, consequentemente, a prática docente.

Vale dizer que as correntes sociológicas se decompõem em outras ramificações, o que faz com que nem todos os autores se identifiquem sob o mesmo designativo. Para averiguar nossa hipótese, apoiamo-nos na literatura franco-luso-brasileira que tem como referência os principais autores da sociologia da socialização, como Durkehim, Berger, Bourdieu e Lahire, e da sociologia pragmática, como Boltanski e Thévenot. Assim, o artigo está dividido em quatro partes. Na primeira parte, veremos como as teorias da socialização enxergam a prática. Na segunda, como a sociologia pragmática entende o mesmo fenômeno social. Em seguida, faremos uma síntese das contribuições das duas correntes sociológicas e, por fim, assinalaremos em quais aspectos as duas abordagens teóricas são complementares e contribuem para a reflexão sociológica sobre as práticas docentes.

\section{Socialização e a teoria da prática}

As teorias clássicas da socialização (DURKHEIM, 1978, 2010; MEAD, 1963) teriam sido deixadas 
de lado por sociólogos do mundo inteiro na década de 1980 por supostamente não serem condizentes com as novas teorias sociológicas em que os indivíduos possuem uma agência na construção do social e de si mesmos. As teorias sociológicas da socialização têm sido atualizadas em sua perspectiva relacional, dialética e dinâmica, o que permite não apenas reconhecer o espaço de ação do indivíduo como levar em consideração sua trajetória para compor os seus recursos de ação.

As "novas" teorias da socialização procuram explicar os mecanismos de transmissão de cultura e de interiorização de valores, normas e papéis sociais que regem a vida em sociedade. Em outras palavras, as teorias da socialização se ocupam das diferentes formas de estar, ser, pensar e agir no mundo através de processos sociais e individuais. Para Abrantes (2011), uma definição simples e completa do conceito de socialização seria:

Processo de constituição dos indivíduos e das sociedades, através das interações, atividades e práticas sociais, regulado por emoções, relações de poder e projetos identitáriosbiográficos, numa dialética entre organismos biológicos e contextos socioculturais. (ABRANTES, 2011)

Tal significado de socialização é decorrente de um estudo das diferentes teorias clássicas e contemporâneas. Esta definição parece acertada, mas é preciso compreender quais são os aspectos mais relevantes das diferentes teorias da socialização para o desenvolvimento deste argumento.

Berger e Luckmann (1985) expõe a socialização como dois momentos diferentes da vida do indivíduo. O mais importante deles é a socialização primária. Ocorrendo nos primeiros anos da vida do indivíduo, a socialização primária possui efeitos duradouros nos traços de personalidade e na construção de uma visão de mundo. O outro significativo, representado principalmente pela família, é o principal responsável pela transmissão de valores e de modos de ser, agir, pensar e sentir. A socialização secundária tem início quando o círculo social da criança se amplia, o que geralmente acontece com a ocupação de outros espaços, como a escola.

A partir de uma releitura da obra de Berger e Luckmann (1985), Darmon (2016, p. 98) argumenta por uma visão contínua do processo de socialização. Assim, a socialização secundária seria um prolongamento da socialização primária, em que o indivíduo atualiza os efeitos da socialização anterior durante toda sua vida. Nesta perspectiva, a socialização contínua pode ter efeitos de conversão ou de confirmação de uma socialização anterior, sendo este um processo sem fim.

Levando em consideração a conceituação de socialização proposta por Abrantes (2011), Pierre Bourdieu é um dos autores relevantes que traz elementos para esta discussão. Sendo seu nome associado à sociologia crítica da qual é fundador, Bourdieu, contribui amplamente para a sociologia da socialização quando expõe os mecanismos de incorporação de valores sociais a partir do desenvolvimento de uma teoria sociológica da ação, preocupando-se com a gênese da conduta humana. Em nossa interpretação, Bourdieu se utiliza de uma metodologia estruturalista, mas nega certos preceitos do estruturalismo teórico como o determinismo e a estabilidade das estruturas, e afirma a existência de uma prática realizada pelos agentes. Além disso, o autor contrapõe-se ao estruturalismo ao possuir um interesse pelas relações entre agentes e instituições e pelas relações de dominação (BOURDIEU, 1989, 1997).

No texto "Esboço de uma teoria da prática" (1983), Bourdieu define o conceito de habitus como sistema de disposições que, associadas ao contexto social do indivíduo, dirige a sua ação, gerando e estruturando suas práticas e representações de acordo com um fim. Segundo Bourdieu, essas disposições de habitus são produzidas a partir da "dialética da interioridade e da exterioridade", que poderíamos resumir na 
interiorização de estruturas sociais de uma configuração social e na exteriorização a partir de ações segundo uma interpretação e um ponto de vista ligados à posição social do agente.

A ação produzida pelo habitus é atravessada por um sentido de jogo, ou seja, uma competência do indivíduo de antecipar as consequências de sua ação a partir de uma leitura dos campos onde ele circula e de agir segundo essa competência e seus interesses pessoais. Nesse sentido, o habitus funciona como uma visão de mundo, uma segunda natureza, é ele que dirige as ações dos indivíduos, como uma estratégia para o alcance de um reconhecimento social. Para Bourdieu, estruturas características de uma configuração social produzem as estruturas de habitus e categorizam as vivências do indivíduo.

Bourdieu, assim como Elias (1994), percebem que as interações entre os agentes são sempre relações de poder. A justificativa bourdieusiana para tanto seria que os agentes estão constantemente em busca de um reconhecimento, ou seja, na luta por um posicionamento social superior ao qual ele se encontra. Os agentes ocupam posições sociais de acordo com o volume de capitais que eles possuem, sendo que aqueles que possuem maior quantidade de capitais são distintos e possuem o poder simbólico de impor suas formas de ser, sentir, agir e pensar aos outros.

Estudos mais recentes no campo da sociologia (LAHIRE, 2002; SETTON, 2016) levam em conta as transformações sociais contemporâneas que classificam as sociedades enquanto pós-modernas e percebem o indivíduo a partir de sua agência, de sua identidade e de sua reflexividade. Compreende-se a socialização a partir de uma perspectiva construtivista enquanto um processo dialógico, em uma perspectiva de mão dupla entre indivíduo e sociedade (SETTON, 2012). Ou seja, os indivíduos possuem capacidades de negociação e resistência, se as condições assim o permitem.

A incompletude do processo de socialização é justificada pela multiplicidade de referências identitárias existentes na sociedade moderna, fazendo com que o processo de individuação seja proporcional às experiências vividas, uma vez que disposições são incorporadas neste processo de forma lenta e reiterada. O uso do conceito de disposições revela a consideração pelo passado e pela trajetória de vida do indivíduo na análise das práticas, por isso esta teoria é também conhecida como sociologia das disposições. Neste sentido, não há condições determinantes, mas condições de possibilidade que fundamentam e estimulam a reflexão, a criação e a transformação de si e do social, por meio das trajetórias de vida dos indivíduos particulares, marcadas por vivências, relações e emoções.

Setton (2012) compreende o processo de socialização como um fato social total segundo uma inspiração maussiana. A partir de pesquisas realizadas no Brasil, a autora percebe a dinâmica relacional, econômica, moral, estética, política e religiosa do fenômeno geral e generalizado da socialização que tem como resultado um conjunto de disposições de ações coerentes, embora fragmentadas e híbridas (idem). Neste sentido, a socialização seria uma forma de garantir a vida em sociedade a partir da interação social e da "reciprocidade de mensagens e bens simbólicos entre agências e agentes socializadores, que envolve simultaneamente todos os indivíduos com a tarefa de manter o contrato e o funcionamento da realidade social" (p. 40).

As instituições pelas quais os indivíduos circulam ao longo da vida são múltiplas como uma consequência do fenômeno da modernidade. O processo de socialização não depende apenas de instituições formais, mas também de instâncias de socialização, como grupo de pares ou cônjuge, a vontade individual ou eventos pontuais, que influenciam na construção de um indivíduo e contribuem para o processo de socialização e de individuação (MARTUCCELLI, 2007). Dessa forma, é possível falar que tanto a socialização primária quanto a socialização secundária são plurais e que há uma hierarquização dos diferentes valores adquiridos no cruzamento de vários processos de socialização (SETTON, 2012), sendo resultados de processos intersubjetivos de "seleção, generalização e analogia" (ABRANTES, 2011). 
Indivíduo e sociedade são compreendidos de forma relacional e dialética, sendo o indivíduo um agente reflexivo que age, interage, sente, negocia, projeta e transforma o social, ao mesmo tempo em que é influenciado por esse (ELIAS, 1994; LAHIRE, 2002). Nesta concepção, as práticas fariam parte de um conjunto de ações que formam um sistema social e que possuem uma lógica e um significado constituídos de um repertório construído a partir de uma história, de um contexto e da reiteração ou da repetição das formas de agir dos indivíduos. Assim, "as práticas organizam (e regulam) a vida social, permitindo uma inscrição social dos sujeitos em quadros coletivos de interdependência e de diferenciação de papéis" (ABRANTES, 2011, p. 126).

De forma sintética, podemos afirmar que a socialização é um processo de incorporação de formas de ser, agir, pensar e sentir que é contínuo e acontece ao longo da vida. Este processo de mão dupla implica negociações do indivíduo com os seus pares, com as instituições e consigo mesmo. Inspirados na ideia de que sociedade e indivíduo não são entidades separadas, a socialização trabalha com o indivíduo e suas relações no sentido mais amplo, ou seja, suas relações com os outros, com os objetos materiais e imateriais que eles fabricam e que são utilizados por eles, e que constituem e forjam os indivíduos e os fenômenos sociais. Desta forma, ela é um processo que permite a construção da sociedade e é acompanhada pelo processo de subjetivação (DUBET, 2007; MARTUCCELLI, 1996), ou seja, da construção de si enquanto indivíduo.

\section{Sociologia pragmática e a conduta humana}

A sociologia pragmática (NACHI, 2012) é uma corrente sociológica que se desenvolve com e contra a sociologia bourdieusiana na década de 1980 na França. Entre os diferentes sociólogos que a representam temos Bruno Latour, Michel Callon, Luc Boltanski, Laurent Thevenot e seus discípulos. Evidentemente, existem diferenças nas contribuições sociológicas de cada um deles, as quais não serão tratadas neste texto. Aqui vamos nos deter nas publicações de Luc Boltanski e de Laurent Thevenot, principalmente no que concerne a sociologia da justificação.

A sociologia pragmática deixa de ser uma sociologia crítica e pretende realizar uma sociologia da crítica (CORRÊA; DIAS, 2016). A sociologia da crítica pressupõe que os atores dispõem de capacidades críticas que são utilizadas de forma cada vez mais frequente na sociedade moderna (BOLTANSKI, 1990, p. 61), sendo o papel do pesquisador trabalhar a partir de uma perspectiva compreensiva na escuta atenta destas narrativas. Ou seja, criticando diretamente a ideia de que os agentes bourdieusianos não teriam consciência do campo social no qual estão inseridos e do sentido objetivo que suas práticas produzem e reproduzem. Para Bourdieu, as estratégias de ação dos agentes seriam inconscientes e, portanto, não podem ser explicitadas pelo próprio indivíduo. Desta maneira, apenas sociólogos e pesquisadores experientes teriam a condição de compreender a motivação das práticas humanas. A sociologia pragmática repudia esta ideia e entende que a função do pesquisador deve deixar de ser desvelar as estruturas de poder (a partir de um olhar de fora para dentro), passando a ter a função de quebrar com uma suposta assimetria entre pesquisador e pesquisado (de dentro para dentro). Ou seja, o pesquisador tem como função recriar da forma mais completa possível o espaço crítico anunciado pelo pesquisado (BOLTANSKI, 1990, p. 63), tendo como finalidade última representar a base normativa dos julgamentos (BLONDEAU; SEVIN, 2004). Neste sentido, concordamos com Benatouil (1999) quando ele afirma que a sociologia crítica está preocupada em saber o que a sociedade faz do homem, enquanto que a sociologia pragmática está interessada em saber o que o homem faz de si mesmo, dos outros e de tudo aquilo que o cerca (seres não humanos e natureza, por exemplo). 
Outro ponto de desacordo entre a sociologia crítica e a sociologia da crítica advém do interacionismo. Enquanto Bourdieu fala em termos de capitais, de habitus e de dominação, Boltanski e sua equipe preferem termos como recursos, tensões e provas. Esse deslocamento tem como objetivo mostrar que as transformações, as mudanças e as incertezas são a "verdade profunda da vida humana" (LEMIEUX, 2008, p. 181). Sendo assim, os atores teriam a possibilidade de ultrapassar as múltiplas contradições de suas ações, produzindo assim uma coerência interna, uma continuidade mínima, uma memória incorporada que propõe tendências do agir (idem, p. 201). Nesse sentido, pluralismo e indeterminação são termos chaves da sociologia pragmática.

Desta forma, os indivíduos são chamados de atores, pois possuem competência, criatividade e capacidade crítica para interpretar e agir em situações quotidianas, rompendo com a ideia da dominação simbólica. A noção de dominação proposta pela sociologia crítica, para Boltanski (2009, p. 41-42), é de um lado muito forte, mas, de outro, muito vaga e não leva em consideração as ações críticas desenvolvidas pelos atores. Para o sociólogo, quando compartilhada com os atores, a ideia de que sua escolha/ação seria motivada por uma dominação poderia ser ofensiva. Ademais, a sociologia crítica partiria do pressuposto durkheimiano de que o mundo seria um fato social, ou seja, já construído, mas para a sociologia pragmática o mundo está sendo construído, portanto o presente, a criatividade e a reflexividade dos atores devem ser levadas em consideração (idem, p. 75). Desta forma, o foco é a observação das pessoas em ação e a justificativa de suas ações para compreender como os atores constroem e se performam no mundo.

Também denominada de sociologia das provas (LEMIEUX, 2008), os estudos desenvolvidos por Boltanski e Thévenot (1991) são definidos como um novo estilo sociológico (NACHI, 2012) que busca colocar em evidência os modos de equivalência, ajustamento e justificação pelos quais os atores produzem os acordos e coordenam suas ações, ou seja, a maneira que eles criam ordens de justiça e às quais eles se referem para denunciar a injustiça. Essa teoria tem como objetivo ser uma nova base de uma sociologia moral, propondo ir além da divisão indivíduo versus coletivo. Sua preocupação é, sobretudo, com as condutas humanas e sua ambição é mostrar a capacidade/competência dos atores em se ajustar a diferentes situações da vida social. Assim, esta corrente teórica propõe a transição de uma sociologia do ator para uma sociologia da ação.

A conduta humana é compreendida e passível de análise por todo e qualquer ator, uma vez que os atores possuem a capacidade de criar dispositivos e recursos a partir de suas próprias ações para o estabelecimento de acordos com os seus pares. Assim, ela é também chamada de sociologia da justificação, pois supõe que os seres são dotados de capacidades morais e que, portanto, são portadores da capacidade de justificar suas ações e, assim, identificar seus próprios valores (JACQUEMAIN, 2001). É a partir de modelos de competência que as pessoas teriam condições de utilizar argumentos para se defender contra injustiças, para fundamentar justificativas de ação, para encontrar acordos ou para denunciar aquilo que consideram injusto.

Os autores da sociologia pragmática partem de teorias da filosofia política para identificar estruturas cognitivas ou princípios de justiça baseados na concepção moral do bem comum superior, em um primeiro nível, e de um conjunto de ações e interações, em um segundo nível. A mediação simbólica e axiológica entre estes dois níveis é denominada cidades/cités (BOLTANSKI, 1990, p. 38). A partir das cidades/cités, é possível fazer uma associação entre a ação com o agir comum, em que "os atores devem fazer uma volta pela cultura e beber no fundo comum das representações coletivas" (VANDENBERGUE, 2006, p. 333). As cidades/cités são padrões de justiça que precedem os indivíduos e que lhes permitem um posicionamento segundo uma medida de grandeza em relação aos outros indivíduos. 
A noção de justiça, em referência a igualdade, é o que permite a articulação entre as utopias políticas e as situações mundanas (CORRÊA; DIAS, 2016). Assim, os princípios de justificação dos atores podem ser mais bem reconhecidos quando analisados durante uma situação pela qual o ator passa, atua e explicita sua ação. Os princípios de referência norteiam a conduta humana a partir de uma apropriação individual do que é construído coletivamente. Dessa forma, a lógica de ação não está atrelada ao ator (diferentemente dos valores), mas às situações vividas por ele no coletivo (JACQUEMAIN, 2001).

As situações (que poderiam ser identificadas como as "conjunturas" na linguagem de Bourdieu), por sua vez, são sequências curtas de ação que estão incluídas em um contexto espacial e temporal, levam em conta as pessoas e as lógicas sociais que preexistem a elas, mas não consideram as estruturas macrossociológicas.

O objeto de uma situação é a prova. A prova desestabiliza o lugar social que o ator ocupa naquela situação e altera aquilo que é ordinário e conhecido, exigindo uma ação do ator e, assim, revelando capacidades cognitivas. Esta noção representa a incerteza e o imprevisível incontestável da modernidade e permite, ainda, compreender o social como problema (CORRÊA, 2014). Desta forma, com a noção de prova, os autores mostram que o conceito de cultura não é harmonioso (BOLTANSKI; THEVENOT, 1991).

Ao estimular uma ação, os princípios de justificação mobilizam determinados valores dos atores que não são sempre coerentes, mas, para sua análise, a sociologia pragmática sugere tipos ideais com a finalidade de melhor compreendê-los. Esses tipos ideais são denominados de lógicas de ação. Elas permitem analisar a conduta humana levando em conta a relação do ator com objetos e o argumento que justifica a ação, ou seja, o sentido de justiça. As lógicas de ação ou lógicas de justificação fazem referência aos modelos de cidades/cités criados pelos autores da sociologia pragmática e são fundamentadas em uma determinada concepção de bem comum.

As lógicas de ação podem ser analisadas a partir das situações que os atores vivem e são compreendidas e justificadas, considerando o princípio de justiça ou da visão de mundo de cada indivíduo, sendo que a lógica argumentativa dos indivíduos está intrinsecamente relacionada com seus princípios de justiça. Compreende-se, assim, os princípios de justiça como um sentido que organiza o mundo social e político dos atores e que orienta as ações suscetíveis de produzir um efeito desejável (GÉGOUT, 2016, p.272).

Por fim, a sociologia pragmática tem a pretensão de levar em consideração a pluralidade de relações que as pessoas estabelecem com as normas e valores (CORRÊA; DIAS, 2016). Estas relações são caracterizadas como adaptações e ajustes da ação em situação, uma vez que elas possuem pretensões universais e possibilitam o julgamento do outro sem a necessidade de interagir em regime de violência (VANDENBERGUE, 2006).

\section{Contribuições das teorias de socialização e da sociologia pragmática}

O objetivo deste item é evidenciar pontos convergentes e dissidentes das duas correntes sociológicas para revelar assim possibilidades de contribuição sociológica quando utilizadas em conjunto.

Um dos pontos de convergências entre as duas correntes sociológicas é a questão da crítica. Enquanto a sociologia da socialização tangencia a sociologia crítica, a sociologia pragmática é 
compreendida por Boltanski (1990) como uma sociologia da crítica. A sociologia crítica de Bourdieu (1989) é uma sociologia que busca desvendar mecanismos simbólicos de reprodução social que estão naturalizados nas sociedades e que, expondo a arbitrariedade com a qual são construídos, permite ao sociólogo propor uma crítica social. Já a sociologia da crítica parte do pressuposto que os atores possuem capacidades e competências para analisar o social e que suas ações prescindem de critérios de justiça e de um julgamento. Assim, o papel do pesquisador é trabalhar a partir de uma perspectiva compreensiva na escuta atenta das narrativas dos atores que revelam injustiças vividas por eles. Ou seja, o julgamento do que é justo ou a crítica ordinária é feita pelo ator, sendo reconhecida e valorizada pelo sociólogo que a transforma em crítica sociológica. A fronteira entre as duas críticas (ordinária e sociológica) é tênue e necessita de uma postura científica e de um distanciamento do pesquisador (BOLTANSKI, 2009). Neste sentido, as duas teorias sociológicas propõem "tornar a realidade inaceitável" (idem, 2009, p. 20) revelando as violências simbólicas no caso da sociologia crítica ou as injustiças ou críticas sociais elaboradas pelos atores no caso da sociologia da crítica. Assim, a crítica é objeto de luta e de transformação social em ambas correntes sociológicas.

Desta forma, não apenas a relação com o sujeito de pesquisa (o pesquisado) é diferente, mas também o indivíduo é compreendido de forma distinta por cada uma dessas correntes. Se por um lado a sociologia pragmática deixa maior espaço para a dimensão indeterminada do mundo, por outro ela pode ser questionada se trouxermos a questão do passado e da história dos indivíduos, uma vez que ela abandona a tradição disposicionalista. A renúncia da história de longa duração realizada com a intenção de se proteger de determinismos faz com que os autores da sociologia da crítica não percebam que nem todos os indivíduos possuem competências, recursos e mecanismos para denunciar as injustiças e, assim, desvelar realidades ocultas e desiguais, como se propõem (BOLTANSKI, 1990, p. 69). As cidades/cités enquanto utopias conceituais não nos auxiliam na compreensão dos recursos utilizados pelos indivíduos, embora admitam uma pluralidade de lógicas de ação que são articuladas segundo os interesses e as estratégias dos indivíduos (DUBET, 2007, p. 100). Em outras palavras, as lógicas de ação dependem da incorporação de determinadas disposições, ou, nas palavras de Derouet (1992, p. 206), de "recursos que são acumulados nas situações anteriores e de rotinas de interpretação e de comportamento nas quais o indivíduo é forjado". Ora, se a sociologia pragmática advoga que a reflexividade é fundamentada pelas experiências sociais dos atores, ela é, então, fundamentada pelo processo de socialização dos indivíduos e, portanto, não pode ser democraticamente distribuída, uma vez que as trajetórias individuais são singulares. Concordamos que a capacidade reflexiva é distribuída de forma igualitária, mas, para que a reflexividade seja desenvolvida, ela necessita de condições sociais de possibilidade e de disposições que permitam o uso da reflexão enquanto um recurso. Ou seja, a escolha das lógicas de ação em situação depende da incorporação de determinadas disposições.

As teorias da socialização, por sua vez, apontam para o fato de que as posições sociais dos indivíduos lhes fornecem instrumentos, capacidades e competências para agir. Contudo, a rigidez de tais posições sociais é questionada, uma vez que ela não corresponde à pluralidade de referências e de situações em que vivemos. Em contrapartida, a sociologia pragmática advoga que estes recursos conceituais, como os capitais e as posições sociais que explicam a diferença de desempenho na ação dos indivíduos, devem servir mais para uma explicação retrospectiva do que para uma previsão prospectiva, uma vez que as disposições não descrevem/ determinam a ação, mas ajudam a prever e a explicar as práticas individuais e a melhor compreender o processo de socialização (BARTHE, 2013).

Chegamos assim no elemento chave que permite a ponte entre as duas abordagens sociológicas - as provas socializadoras. As situações de prova são entendidas aqui como o objeto de análise ideal para a articulação entre as disposições e as lógicas de ação. As ações em situação favorecem a compreensão das disposições dos atores que foram constituídas a partir da trajetória de vida do ator, e, ao mesmo tempo, as 
mesmas situações revelam uma escolha, dentre as múltiplas formas de agir em situação. Esta escolha não é neutra; ela depende do passado do ator, de suas disposições internas, mas também do presente, uma vez que as situações são complexas e constituídas por uma variedade de fatores externos (incertezas, interação com os outros, recursos disponíveis etc). Desta forma, a reflexividade do ator em situação faz com que ele privilegie uma ou outra lógica de ação levando em consideração as suas disposições incorporadas. A análise deste processo é facilitada quando as situações são utilizadas enquanto uma ferramenta metodológica para o estudo da ação, uma vez que elas delimitam o espaço da prática humana e permitem compreender as ações individuais.

Cumpre salientar que as instituições possuem uma forma permanente e dinâmica de relação entre si, que podem agir em sinergia de valores ou apresentar visões de mundo opostas (SETTON, 2012). Estas instituições ou estruturas sociais permitem que o indivíduo passe por uma série de provas que forjam o indivíduo enquanto indivíduo (MARTUCCELLI, 2007) e lhe oferecem ferramentas para que ele participe da construção da sociedade; assim, socialização e individualização fazem parte de uma mesma matriz (SETTON, 2016).

A socialização, então, não é apenas o resultado de uma prática de transmissão simbólica, agenciada e finalizada por um ou vários atores e agências institucionais. Este processo é também um trabalho cognitivo, sócio afetivo do indivíduo, que dá sentido à sua trajetória, às suas atividades e aos seus espaços de referência, em contextos de incertezas, pluralidade e mobilidade. A socialização constitui a mediação do indivíduo com a sociedade a partir do processo de integração e de adaptação às exigências sociais e, ao mesmo tempo, permite ao indivíduo construir sua identidade.

Em tempos modernos, podemos afirmar que as teorias clássicas da socialização falharam ao não levar em consideração a pluralidade de valores, de contextos, de disposições individuais e de emoções. Enquanto isso, a sociologia pragmática falha ao desconsiderar duas proposições elisianas: a configuração social e que toda relação é uma relação de poder. As novas sociologias da socialização permitem trabalhar com e a favor da sociologia pragmática, levando em consideração as estruturas sociais, o indivíduo, a história, o presente e os princípios de justiça a partir da ação em situação e a pluralidade das trajetórias sociais sem reduzi-las ao jogo do coletivo de forma automática e direta.

Assim, a ação em situação depende, de um lado, de disposições dos atores adquiridas em sua trajetória de vida, na qual o ator passa por provas socializadoras, e, de outro, de uma escolha não neutra de uma lógica de ação que acontece no presente, levando em consideração os atores humanos e não humanos envolvidos na situação. As disposições individuais fundamentam a escolha da lógica de ação, mas a incerteza e a complexidade específica da situação impõem a necessidade de mobilizar a reflexividade para levar em conta as diversas dimensões que estão envolvidas na situação e ainda calcular as possíveis consequências desta ação.

\section{A análise das práticas docentes a partir de duas correntes sociológicas}

Tanto as sociologias da socialização quanto a sociologia pragmática concordam que as práticas são os motores do mundo, formadoras e constitutivas da realidade social e da construção do indivíduo que está sempre em interação. Conceito importante para as duas correntes sociológicas, a prática é entendida como um conjunto de atividades situadas, que está intimamente relacionada a um verbo ou uma ação que é motivada por projetos ou valores e que é consequência de um hábito ou de uma reflexão. 
As práticas docentes formam um conjunto de ações visíveis e invisíveis que resulta do acúmulo de saberes e valores profissionais e pessoais que são construídos através de trocas, de formações e de experiências, ou seja, de provas socializadoras. A profundidade e a complexidade das práticas docentes são consequências dos múltiplos aspectos que atravessam o ofício de professor, notadamente uma série de recomendações e de injunções.

A prática docente seria entendida pela sociologia estruturalista como correspondente às políticas públicas e normas estatais. A sociologia pragmática fornece indícios para revelar que os professores se posicionam mediante as ordens recebidas e fazem uma crítica às decisões vindas de cima (RESENDE; DIONÍSIO, 2016, p. 205). Isso acontece em parte por conta da dupla relação dialógica entre trabalhador versus profissão e contexto social (DUBAR, 2005). Ou seja, a profissão supõe uma maneira de ser e agir e, desta forma, constrói os seus profissionais a partir de um processo de socialização profissional. Isso garante que a prática profissional seja uma prática coletiva e constitui uma cultura profissional. Contudo, os profissionais, a partir de disposições incorporadas, possuem recursos para construir a seu próprio estilo profissional (CLOT, 2008), levando em conta seus pares, suas funções, a visão que ele possui da sua profissão e as incertezas inerentes às relações sociais. É desta forma que, na relação com os pares e nas experiências profissionais de forma fluida e não intencional, os professores criam possibilidades de ação que buscam um equilíbrio entre o que é prescrito e o que é praticado, o que é chamado de agir criativo por Joas (2004) e que está presente em diferentes âmbitos da profissão, seja na transmissão de conteúdos ou no modo de se relacionar com os alunos. Isso acontece, segundo Dubet (2007, p.74), "para que a atividade seja possível e seja compartilhada pelos membros de uma mesma sociedade, é preciso que os indivíduos adiram a princípios de justiça comuns suscetíveis de constituir uma base normativa para seus argumentos e debates".

O processo de socialização profissional faz parte da trajetória de vida do professor, na qual a modernidade interfere diretamente, uma vez que a dessacralização da instituição escolar significa que o trabalho docente pode receber críticas exteriores (alunos, pais, mídias, avaliações nacionais e internacionais), que, por sua vez, podem representar provas socializadoras para a construção identitária do profissional. Desta forma, são legitimados novos modelos de autoridade docente e exige-se uma plasticidade dos docentes para lidar com imprevistos que acrescentam experiências profissionais para a construção de uma identidade profissional e da profissionalização docente (LANTHEAUME; HÉLOU, 2008, p. 50 e p. 95). Esta plasticidade implica uma capacidade reflexiva de um ator social, com capacidade de leitura dos processos sociais que vive (BOLTANSKI; THÉVENOT, 1991).

Tal capacidade se configura com as disposições adquiridas ao longo da socialização contínua do docente que lhe fornece recursos para agir em situação que é, por sua vez, socializadora e capaz de modificar, acrescentar ou transformar as disposições, tornando-as ainda mais híbridas e plurais (LAHIRE, 2002; SETTON, 2016). Neste sentido, não é possível falar na existência de um habitus docente (SETTON, 2011), mas de uma pluralidade deles. Desta forma, as disposições docentes plurais que serão mobilizadas nas ações dos atores reforçam a pluralidade de lógicas que estão intimamente ligadas às incertezas próprias de uma sala de aula e à(s) relação(ões) estabelecida com os outros atores em situação (alunos, pais de alunos, colegas, autoridades escolares).

A reflexividade é também mobilizada para justificar as ações docentes e desvelar aquilo que os professores entendem como injusto não apenas na escola onde trabalham mas também na configuração sociocultural onde vivem. E é seguindo seus valores e princípios de referência que os professores, de agentes, se tornam atores, subjetivando a si próprios e lutando segundo seus próprios valores dentro da escola, transformando assim a sua prática docente em uma prática política e, consequentemente, contribuindo para a construção de sua própria profissão. 
As múltiplas referências que caracterizam as sociedades modernas e que atuam no processo de hibridização, de incorporação e de hierarquização de disposições profissionais e pessoais dos docentes, bem como grande parte do seu trabalho real, acabam sendo invisíveis. A sociologia da socialização e a sociologia pragmática nos fornecem instrumentos para (1) identificar o processo de aquisição das disposições docentes coletivas e individuais a partir de uma retrospectiva histórica e relacional do indivíduo; (2) possibilitam compreender as práticas docentes a partir da explicitação de situações, nas quais os docentes justificam suas escolhas de ação e apontam um regime de justiça, revelando seu engajamento moral e ético; e, por fim, (3) a análise das situações torna factível o estudo do trabalho real do docente, em que há um compartilhamento das dificuldades do ofício através de uma narrativa reflexiva e de justificação e que permite que o pesquisador esteja ao lado (e não acima) do profissional em uma escuta compreensiva.

Vale pontuar que na área da sociologia da educação, a sociologia da socialização fundamenta estudos de autores brasileiros, portugueses e franceses (SETTON, 2012; 2016; KNOBLAUCH, 2014; SEFTON, 2013; THIN, 2010; DUBAR; 2005; ABRANTES, 2013; TORRES, 2018). A significativa quantidade de trabalhos que segue esta corrente sociológica poderia ser explicada pela sua grande circulação, renovação e apropriação. Já os estudos que mobilizam a sociologia pragmática na área da educação são menos expressivos. O primeiro deles foi publicado em 1992, na França sob o título École et justice De légalité des chances aux compromis locaux? de Derouet e abriu portas para outros (RESENDE, 2005; LANTHEAUME; HÉLOU, 2008). A conciliação entre as duas teorias sociológicas é um desafio novo para a sociologia da educação que foi explorado, em parte, na obra do sociólogo francês Dubet (2007), embora ele não denomine seus estudos desta forma, e em uma tese de doutorado brasileira (VALENTE, 2019).

\section{Considerações finais}

Não se pretendeu fazer um estudo extensivo das duas teorias sociológicas, mas pensar como a sociologia da socialização e a sociologia pragmática possuem contribuições teóricas e metodológicas para a discussão das práticas docentes atuais, levando em conta sua complexidade. Nesse sentido, a socialização profissional plural e as disposições dos professores são compreendidas como uma dimensão biográfica que revela sentidos e justifica a prática docente em situação, que, por sua vez, fornece elementos para a socialização profissional dos docentes em um círculo virtuoso. Neste sentido, as diversas facetas das práticas docentes são mais bem analisadas e compreendidas ao utilizarmos elementos das duas abordagens teóricas aqui expostas, relevando as contribuições sociológicas de cada uma delas.

Assim, entendemos que a sociologia pragmática faz um esforço para superar a sociologia da socialização. Sem dúvidas, ela se apresenta como um avanço para o pensamento sociológico. Contudo, o jogo acadêmico e científico de superar verdades, por vezes, esquece que olhamos sobre ombros de gigantes, ou seja, conceitos e entendimentos da sociologia da socialização não devem ser descartados. Pelo contrário, a conjunção de tais conhecimentos possibilita enriquecer estudos teóricos e metodológicos e, como mostramos aqui, traz contribuições para a sociologia da educação e para estudos sobre as práticas docentes.

\section{Referências}

ABRANTES, P. Para uma teoria da socialização. Sociologia, Revista da Faculdade de Letras da Universidade do Porto, Vol. XXI, 2011, pág. 121-139 
ABRANTES, P. A Escola da Vida: Socialização e Biografia(s) da Classe Trabalhadora. Lisboa, Mundos Sociais. 2013.

BARTHE, Y. et al., Sociologie pragmatique : mode d'emploi, Politix 2013/3 (Nº 103), p. 175-204. https://doi. org/10.3917/pox.103.0173

BÉNATOUİL, T. Critique et pragmatique en sociologie. Quelques principes de lecture. Annales. Histoire, Sciences. Sociales. 54 année, N. 2, 1999. pp. 281-317. https://doi.org/10.3406/ahess.1999.279749

BERGER, P.; LUCKMANN, T. A construção social da realidade - tratado de sociologia do conhecimento. Petrópolis: Vozes 1985 [1966].

BLONDEAU, C.; SEVIN, J-C. Entretien avec Luc Boltanski, une sociologie toujours mise à lépreuve ». ethnographiques.org, Numéro 5 - avril 2004 [en ligne].

BOLTANSKI, L. L’amour et la justice comme compétences. Trois essais de sociologie de l'action. Éditions Métailié, 1990. 547p. https://doi.org/10.3917/meta.bolta.1990.01

BOLTANSKI, L.; THÉVENOT, L. De la justifcation: les économies de la grandeur. Paris: Gallimard, 1991.

BOLTANSKI, L.; De la critique. Précis de sociologie de l'émancipation. Éditions Gallimard, 2009. 291p.

BOURDIEU, P. Esboço de uma teoria da prática. In: ORTIZ, R. (org.). Pierre Bourdieu: Sociologia. Trad. de Paula Montero e Alícia Auzmendi. São Paulo: Ática, 1983 a, p. 46-81.

BOURDIEU, P. O poder simbólico. Lisboa: Difel, 1989.

BOURDIEU, P. Méditations pascaliennes. Paris: Seuil. 1997.

CLOT, Y. Travail et pouvoir d'agir, Paris : PUF, 2008. 312p.

CORRÊA, D. Do problema do social ao social como problema: elementos para uma leitura da sociologia pragmática francesa. Revista de Ciências Sociais, n. 4, abril de 2014, pp. 35-62.

CORREAA, D.; DIAS, R. Crítica e os momentos críticos: de la justification e a guinada pragmática na sociologia francesa. Mana, 22(1): 2016, p. 67-99. https://doi.org/10.1590/0104-93132016v22n1p067

DARMON, M. La socialisation. Armand Colin : Paris, 2016.

DEROUET, J-L. École et Justice. De l'égalité des chances aux compromis locaux ? Éditions Métailié, Paris, 1992. https://doi.org/10.3917/meta.derou.1992.01

DUBAR, C. A socialização: construção das identidades sociais e profissionais. Tradução Andréa Stahel M. da Silva. São Paulo: Martins Fontes, 2005 [2000].

DUBET, F. L'expérience sociologique. Paris: La découverte. 2007.

ELIAS, N. A sociedade dos indivíduos. Rio de Janeiro. Editora Zahar, 1994 [1987].

GÉGOUT, P. La bienveillance comme valeur pratique pour enseigner. In : FABRE, M. et al. L'idée de valeur en éducation. Sens, usages, pertinence. Hermann, Paris, 2016.

JAQUEMAIN, M. Les cités et les mondes: le modèle de la justification chez Boltanski et Thévenot. 
Département de sciences sociales de l'Université de Liège. 2001. Disponível em : https://orbi.uliege.be/ bitstream/2268/90443/1/Les\%20cit\%C3\%A9s\%20et\%20les\%20mondes\%20de\%20Luc\%20Boltanski.pdf Acesso em 15/01/2017.

JOAS, H. La créativité de l'agir. In: BAUDOUIN, J. et FRIEDRICH, J. (Eds). Théories de l'action et éducation (pp. 27-43). Genève : Raisons Éducatives. 2001. https://doi.org/10.3917/dbu.baudo.2001.01.0027

KNOBLAUCH, A. Relação entre religião, gosto por criança e mudança social: a escolha por Pedagogia. In: Benedita Portugal e Melo; Ana Matias Diogo; Manuela Ferreira; João Teixeira Lopes; Elias Evangelista Gomes (Org.). Entre crise e euforia: práticas e políticas educativas no Brasil e em Portugal. 1ed.Porto: Universidade do Porto/Faculdade de Letras, 2014, v. , p. 69-92.

LAHIRE, B. Homem plural - os determinantes da ação. Petrópolis. Editora Vozes. 2002. [1998].

LANTHEAUME, F; HÉLOU, C. La souffrance des enseignants. Une sociologie pragmatique du travail enseignant. PUF, Paris, 2008. https://doi.org/10.3917/puf.lanth.2008.01

LEMIEUX, C. De la théorie d'habitus à la sociologie des épreuves : relire L'expérience concentrationnaire. In : ISRAEL, L.; VOLDMAN, D. Michael Pollak. De l'identité blessé à une sociologie des possibles. France : Editions Complexe. 2008.

MARTUCCELLI, D. Cambio de Rumbo: la sociedad escala del individuo. Santiago: Lom Ediciones, 2007.

NACHI, M. Introduction à la sociologie pragmatique. Armand Colin : Paris, 2012.

RESENDE, J. M. La reconnaissance publique des différences et de la justice scolaire : de la sociologie critique à la sociologie de la critique, Education et sociétés 2005/1 (no 15), p. 137-152. https://doi.org/10.3917/ es.015.0137

RESENDE, J. M. DIONÍSIO, B. Itinerários à luz da Sociologia Pragmática: o que os lugares comuns trazem à comunalidade escolar Terceiro Milênio: Revista Crítica de Sociologia e Política. Volume 6, número 1, janeiro a junho de 2016.

SEFTON, A. P. Prática docente e socialização escolar para as diferenças: um estudo sobre estratégias de transformação da ordem em gênero e sexualidade. Tese de doutorado. Faculdade de Educação da Universidade de São Paulo. 2013.

SETTON, M. Prática docente: algumas questões do campo sociológico. InterMeio: revista do Programa de Pós-Graduação em Educação, Campo Grande, MS, v.17, n.33, p.175-182, jan/jun. 2011.

SETTON, M. Socialização e Cultura: ensaios teóricos. São Paulo: Annablume, 2012.

SETTON, M. Socialização e individuação. A busca pelo reconhecimento e a escolha pela educação. São Paulo: Annablume, 2016.

THIN, D. Famílias populares e instituição escolar: entre autonomia e heteronomia. Educação e pesquisa, v.36. 2010. https://doi.org/10.1590/S1517-97022010000400006

TORRES, L. Culturas de escola e excelência: entre a integração de todos e a distinção dos melhores. Revista de Sociología de la Educación (RASE), vol. 11, n. 1, 2018. pp. 167-185. https://doi.org/10.7203/RASE.11.1.10619 
VALENTE, G. As práticas docentes e a questão religiosa Elementos de comparação entre o Brasil e a França. Tese (Doutorado em Educação). Faculdade de Educação. Universidade de São Paulo. P.295. 2019.

VANDENBERGUE, F. Construção e crítica na nova sociologia francesa. Sociedade e Estado, Brasília, v. 21, n. 2, p. 315-366, maio/ago, 2006. https://doi.org/10.1590/S0102-69922006000200003

\section{Sobre a Autora}

Gabriela VALENTE é pós-doutoranda na Université Lumière Lyon 2, doutora em Educação pela USP e pela Université Lumière Lyon 2. Na área de sociologia da educação, pesquisa temas que envolvem a escola pública, a prática docente, a diversidade cultural, a religiosidade e o Estado laico.

Recebido: 02 Maio 2019

Aceito: 04 Dez 2019 